\title{
Tropylium, Chlorine Isotopic Abundances, Monomeric Metaphosphate Anion, and Conestoga Wagon Theory*
}

\author{
Seymour Meyerson ${ }^{\dagger}$ \\ Research Department, Amoco Corporation, Naperville, Illinois, USA
}

\begin{abstract}
As I look back over a career in mass spectrometry, three high points stand out especially prominently. These are associated with (1) the tropylium model for the $\mathrm{C}_{7} \mathrm{H}_{7}^{+}$ion in the mass spectra of toluene and other alkylbenzenes, (2) revision of the previously accepted value for the natural abundance of the chlorine isotopes, and (3) the first direct observation of the monomeric metaphosphate anion, which had been for a quarter of a century an elusive, suspected reaction intermediate. Studies of organic ions in the rarefied atmosphere of the mass spectrometer, where only unimolecular processes are allowed, have deepened my appreciation of the role and ubiquity of bimolecular processes in more conventional chemical contexts. Consideration of the two categories of molecular behavior has prompted me to seek and find, for a selected system in the mass spectrometer, parallels both in condensed-phase chemistry and, by an anthropomorphic extension, in human behavior. (f Am Soc Mass Spectrom 1993, 4, 761-768)
\end{abstract}

$\mathrm{I}$ have been retired for 9 years now. Before that I worked in mass spectrometry for the Amoco Corporation, under various corporate names, for 37 years. The accompanying photographs, Figures 1 and 2 , respectively, reflect the aging-or maturingprocess over those years. The first was taken in 1948, shortly after I joined the then Standard Oil Company (Indiana); the second in 1984, a few weeks before retiring. It's been a great life, and I feel that I have been extraordinarily fortunate. I feel deeply honored to have been selected as the 1993 recipient of the Frank H. Field and Joe L. Franklin Award for Outstanding Achievement in Mass Spectrometry. I extend thanks to Frank Field and Joe Franklin for helping to inspire the establishment of the award and for lending their names to it, to Extrel Corporation for supporting it financially, to the American Chemical Society, and to all of the people who played a part in bringing about this occasion for me. I feel especially honored to be the first recipient from industry rather than academia in a field the foundations of which were laid down so largely in industrial laboratories. I appreciate, however, that some of my predecessors spent a part of their professional

*Based on an address given on receiving the Frank H. Field and Joe L. Franklin Award for Outstanding Achievement in Mass Spectrometry at the 205th National Meeting of the American Chemical Society, Denver, CO, March 30, 1993.

$\uparrow$ Retired 1984 .

Address reprint requests to Seymour Meyerson, $650 \mathrm{~N}$. Tippecanue Street, Gary, IN 46403.

careers in industrial research before moving into the academic world.

\section{Reminiscences}

Trying to decide what sort of remarks properly belong in an award address, I have been thinking back over all those years. A few of the many high points that I have experienced stand out especially prominently in my memory and reviewing them may be apropos.

The first of the items that I want to describe goes back to the very beginning of my exploratory program, about 1955. At that time I was working closely with Henry Grubb and Paul Rylander, to both of whom I am deeply indebted for their contributions to my early growth as a researcher into molecular behavior. I start with tropylium. In seeking clues to help answer a number of questions in the mass spectrometry of alkylbenzenes, we noted that the American Petroleum Institute-National Bureau of Standards (NBS) reference spectra of toluenes labeled with a single deuterium atom in all four possiblc positions are nearly indistinguishable. In fact, the people at the NBS, who had contributed these spectra, had commented on this curious circumstance but had offered no rationale that might make sense of it [1]. In any case, we repeated their work, preparing and measuring the mass spectra of the four deuterotoluenes, plus toluene- $\alpha-d_{3}$ and a series of deuterated ethylbenzenes, and we proposed ring enlargement to account for the loss of identity of 


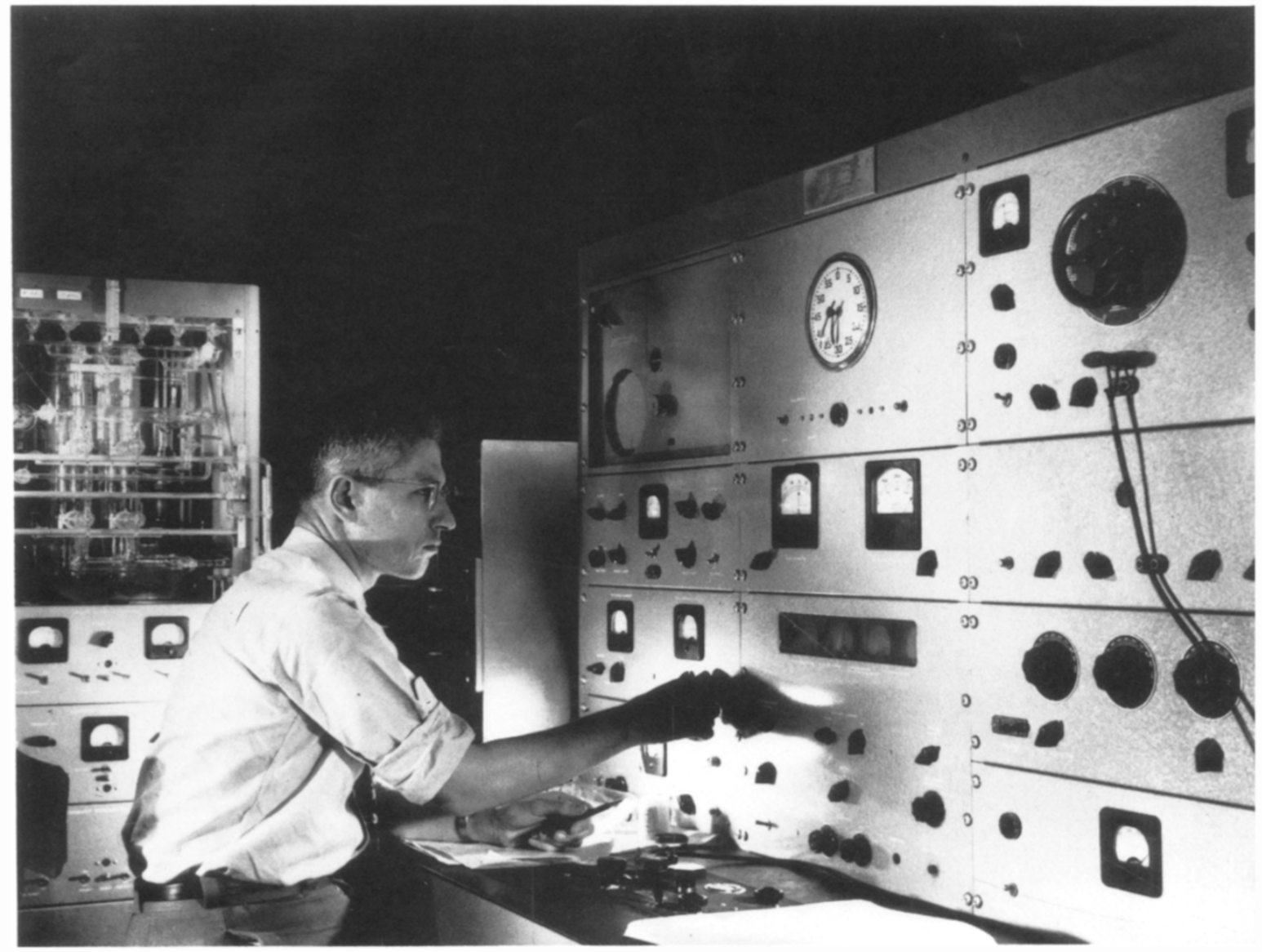

Figure 1. The author at the console of a Consolidated model 21-102 mass spectrometer in Standard Oil's then new Whiting Research Laboratories, Whiting, Indiana, 1948.

all the hydrogen atoms in the dominant decomposition path [2]:

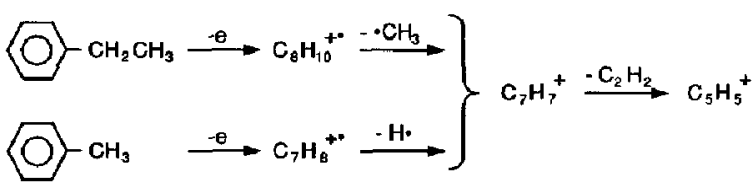

Thus, we pictured $\mathrm{C}_{7} \mathrm{H}_{7}^{+}$as the tropylium ion:<smiles></smiles>

After publishing this work, we proceeded to check our interpretation via ${ }^{13} \mathrm{C}$-labeling, working with $\mathrm{C}_{6} \mathrm{H}_{5}^{13} \mathrm{CH}_{3}$ [3]. If the seven carbons in $\mathrm{C}_{7} \mathrm{H}_{7}^{+}$are in fact indistinguishable, we reasoned that loss of $\mathrm{C}_{2} \mathrm{H}_{2}$ should produce a $\mathrm{C}_{5} \mathrm{H}_{5}^{+}$product that retains the label five times in seven; that is, enrichment should be $71 \%$. As soon as I had the data, I phoned Rylander and reported that our experimental value for the enrichment was $69 \%$, to which he responded, "Ain't it grand when Nature's on your side!"

Initially, our tropylium proposal drew a mixed reception. Bob Burwell, of Northwestern University, at the end of a half-day in 1955 that we spent talking about our tropylium hypothesis and the accompanying story on cationated cyclopropanes [4], urged us to submit the material for presentation and publication [5]. "I would estimate," he opined, "that these proposals of yours may have a life of ten years, and for theories of organic reaction mechanisms that's a long life. Moreover, they may even be right." On the other hand, John Kinder, of Sinclair Research, after hearing our tropylium presentation before the 1956 annual 1-day meeting of the then Midwest Spectroscopic Group, responded in frustration, "Do you realize what you'rc saying? If what you are saying is true, we can't believe anything the mass spectrometer tells us any 


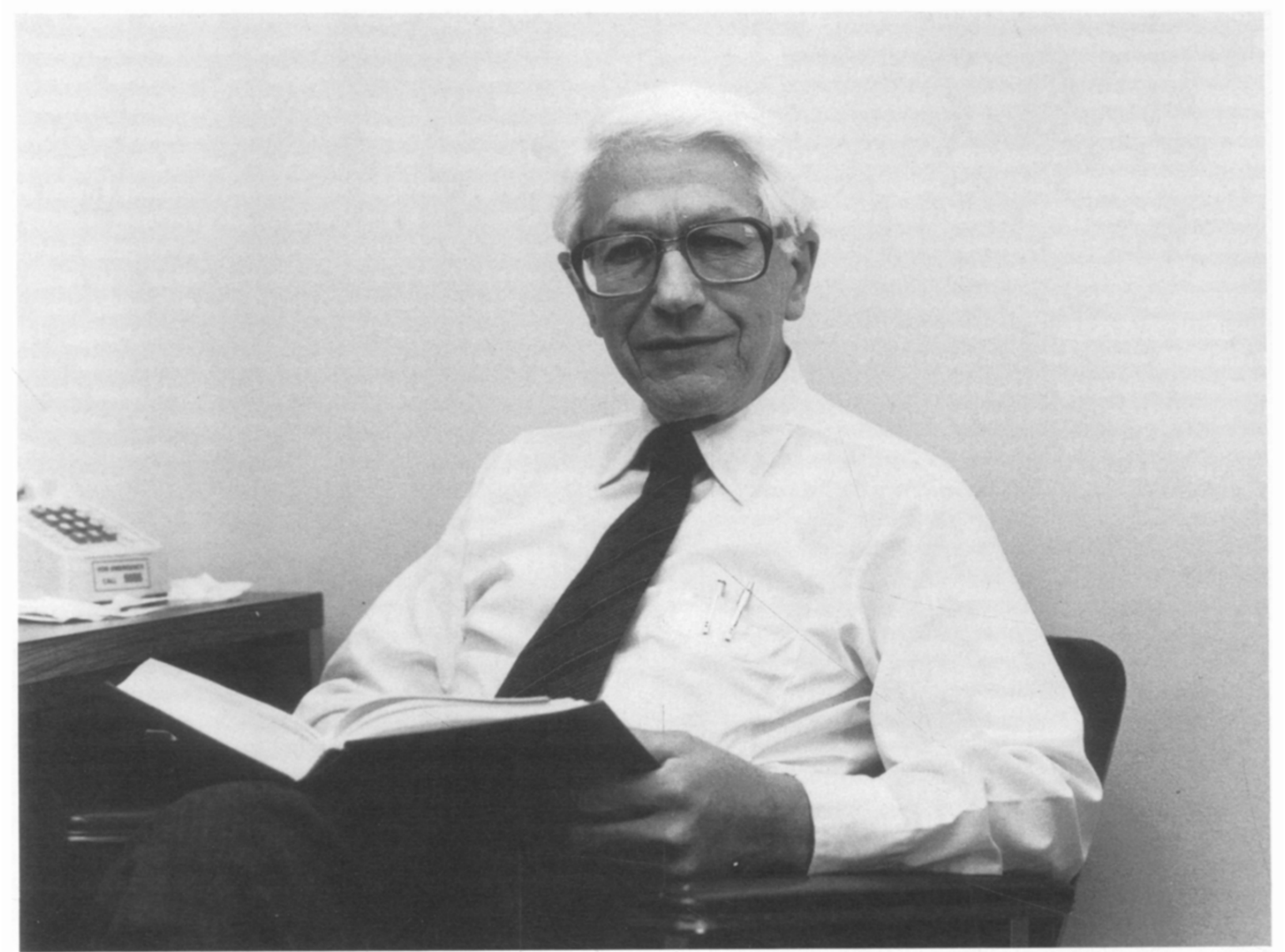

Figure 2. The author in April 1984 in his office at the Amoco Research Center, Naperville, Hilinois, shortly before retirement.

more." Subsequently, tropylium rapidly gained almost universal acceptance, and the mechanistic details of the process have been the subject of a great number of investigations since then. At the 1978 Annual Conference on Mass Spectrometry and Allied Topics, Ben Freiser, of Purdue University, introduced his and McCrery's paper [6] with the commenl, "The $\mathrm{C}_{7} \mathrm{H}_{7}^{+}$ cation continues to be a favorite structure problem, which all mass spectrometrists sooner or later focus in on and try to understand better."

My second high point hinges on work that I described in an Analytical Chemistry letter in 1961 on the natural abundance of the chlorine isotopes [7]. In a problem that I was working on, I needed the isotopic composition of a sample of deuterated $p$ chlorobiphenyl. Correcting the parent-peak intensities in low-voltage spectra of the unlabeled compound for naturally occurring isotopes led to consistently negative residues at a mass number $2 \mathrm{u}$ above that of the most abundant species. The discrepancy implied an inconsistency between my data and the assumed distribution of the chlorine isotopes, the then generally accepted value as found in reference tables. To pinpoint the problem, I proceeded to calculate what the distribution would have to be to remove the discrepancy, using 10 pairs of peaks selected from the mass spectra of three chlorine compounds that I took off the shelf. These measurements yielded $75.80 \%$ of the ${ }^{35} \mathrm{Cl}$ isotope, with an average deviation of $0.06 \%$, as upposed to the value of $75.4 \%$ from the reference tables. A year after my letter appeared, a group at the NBS published their redetermination of the chlorine isotopic abundances, taking the exhaustive precautions that are properly called for in such a measurement [8]. Their result for ${ }^{35} \mathrm{Cl}$ abundance, which remains the standard reference value today, is $75.770_{5} \%$, with estimated error limits of $+0.044 \%$ and $-0.046 \%$. Agreement with my value is well within the combined uncertainties.

My third high point came some years later in work with collaborators at the National Institute of Environmental Health Sciences (NIEHS), University of North Carolina at Chapel Hill, and the State University of New York at Stony Brook. In 1978 a group at the 
NIEHS reported mass spectra, measured by a variety of experimental techniques, of several organophosphorus pesticides [9]. Negative ion chemical ionization spectra of some of these compounds contained a prominent peak at $m / z 79$. I suspected that this peak might well be attributable to $\mathrm{PO}_{3}$, the monomeric metaphosphate anion to which I had been sensitized by my longtime friend and collaborator Fausto Ramirez, an organic chemist with a special interest in organophosphorus chemistry. This molecule was first proposed in $\mathbf{1 9 5 5}$ as an intermediate in hydrolysis of phosphomonoesters in aqueous solution [10], and the hypothesis was later extended to include other reactions and additional monomeric metaphosphate species as intermediates [11]. Despite a vast amount of research effort, the monomeric metaphosphate anion continued to elude observation and to evoke references to an "evanescent" [12] or "mythical" [13] intermediate. With this history in mind, I promptly phoned the authors of the NIEHS paper to alert them to the potential significance of the peak at $m / z$ 79. Subsequent precise mass measurement on that peak in the spectra of two of the pesticides studied established $\mathrm{PO}_{3}^{-}$ unequivocally as the source of $99.9 \%$ of the observed intensity [14]. A literature review [15] showed that over the intervening period of nearly a quarter of a century phosphate chemists had been seeking to establish the existence of this theoretical construct and that during this same period of time, mass spectrometrists had created an extensive literature on organophosphorus compounds in which we found a great deal of evidence for monomeric metaphosphate species but with no explicit reference to any such species. Thus, organic chemists and mass spectrometrists interested in organophosphorus compounds had worked in isolation from each other all these years, quite oblivious to each others' concerns even when they were working with similar or identical compounds. Our direct observation of the $\mathrm{PO}_{3}^{-}$ion, an outgrowth of my happy collaboration with Ramirez, brought this state of affairs to an end and gave the two of us and our other collaborators a deep sense of satisfaction.

For the remainder of what follows, I have taken the liberty, in view of my present status as a retiree and no longer an active researcher, of assembling some thoughts that might perhaps qualify as a semitechnical report.

\section{Reflections on the Psychology of Molecules: The Conestoga Wagon Theory}

All of us who work with mass spectrometers know that these machines are human, at least in some respects. I want to argue today that the same can be said of the molecules that we use the machines to observe.
On emerging from the army in late 1946, I was faced with the question, "Where do I go from here?" I had behind me a B.S. degree in chemistry from the University of Chicago plus a few graduate courses-a good academic record, but I had not been in a chemistry laboratory for 5 years. In addition, the Army Signal Corps, between the Enlisted Reserve Corps and active service, had put me through excellent courses in electronics and ultrahigh frequency techniques, including practical training in radio and radar, but none of my subsequent military assignments made use of this training. So at the time of my discharge, both my chemistry and electronics were pretty rusty. I reasoned that if I could find a job that combined the two fields, an employer who might decide to gamble on me would stand a better chance of getting an early return on his investment than in either field alone. On this basis, E. B. Tucker at Standard Oil Company (Indiana)-now Amoco Corporation-pointed me toward the then very new discipline of mass spectrometry and brought me into the Analytical Division of the Research Department in Whiting. Another factor entered into Tuck's decision. During a period of uncertainty in the late depression, after receiving my B.S. degree I spent a year or so taking courses in sociology, social psychology, comparative religion, and informal education and recreation. Interviewers at other companies had seen this part of my resume as a waste of time and a sign of indecisiveness. In rontrast, Tuck took the view that whatever I might have learned that might help me to better understand what makes people act as they do would be valuable in working in the organization there. I don't think he foresaw that my exposure to the social sciences might also influence the way I viewed molecular behavior.

In any case, my interest in the social sciences stayed with me, and it was reinforced by the fact that my wife's college major was sociology, and her lifelong interests have been centered in the social sciences, with no feel at all for molecules and atoms. Hence, if I had any hope of conveying to her a sense of the fun and excitement that I experienced in the laboratory, I had to find ways to use the language and concepts that are familiar to her. Accordingly, through the subsequent years, I sought and often found parallels between the behavior of molecules and of people. Such anthropomorphism is not fashionable in the scientific community, and I make no claim of profundity for the practice, but it does enable one to look at both molecules and people from unusual angles, which may contribute some added insights to both contexts.

Other contributors to the chemical literature have amused themselves similarly, despite the general disapproval of editors. Two delightful examples occur in John Leffler's book, The Reactive Intermediates of Organic Chemistry [16]. The first appears in a discussion of the cage effect, in which dissociation products of a molecule in solution may recombine and thus reconstitute the original molecule before they can escape from 
the cage formed by the surrounding solvent molecules. Leffler rechristens this behavior as the "Hardy effect," with a footnote citing Thomas Hardy's The Return of the Native (ref. 16, p 130). In a second example, when an electrophilic, or electron-seeking, particle attacks an electron-rich particle, Leffler describes the product as having attained a "psychological state of electrofelicity, or electron-bliss" (ref 16, p 117).

Harold Wiley, who was a key member of the Consolidated Engineering Corporation team and its successor organizations from its start in about 1940 until his retirement in 1970, shared my weakness for this form of amusement. Some 10 years ago he went through his accumulated files to select items that might be helpful to me for a historical review of organic mass spectrometry that I was then assembling [17]. Among the documents he found and sent to me were some doodles that he had drawn back about 1943 during evenings spent in hotel rooms when he was in the field struggling with the installation of the first several model 21-101 instruments in customers' laboratories. Figure 3 shows one of them. The "Sibyl" referred to there is Sibyl Rock, who contributed heavily to Consolidated's users' manuals, especially those concerned with calculations. Recall that the principal single use made of analytical mass spectrometers at that time was for quantitative analysis of mixtures of light hydrocarbons and fixed gases. A molecule containing seven carbons was likely to cause serious interference.

Let me take just a moment to describe the experimental system embodied in the mass spectrometer, in case any readers are not already thoroughly familiar

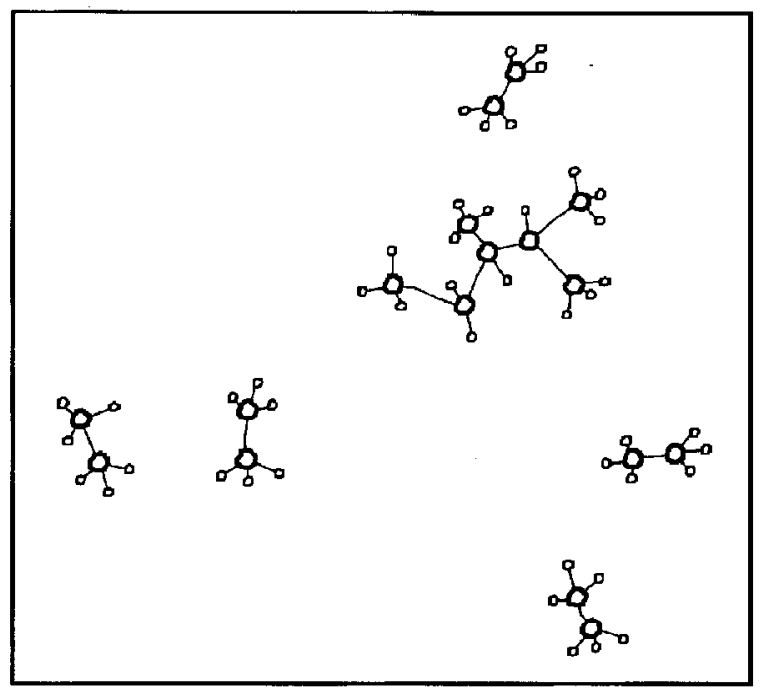

MY GOD! WILL SIBYL BE SORE

WHEN SHE SEES HIM WITH US!

Figure 3. See text for explanation. For the benefit of any nonchemist readers, the large circles denote carbon atoms; the small circles, hydrogen. with this instrument. A stream of molecules flowing through an evacuated chamber is subjected to impact by a beam of electrons (for a brief primer of mass spectrometry, see ref. 18). Some of the hits result in ionization-removal of an electron from an originally electrically neutral molecule, leaving a net positive charge-and many of the ionized molecules also receive enough excess energy from the impact to cause dissociation to molecular fragments, a mix of charged and neutral particles. The instrument sorts the ions by mass and reports the resulting distribution, which we call a mass spectrum. These spectra and other, related, measurements can give us information about the composition of the material under study, and, in addition, they can throw light on details of the ionization and dissociation processes induced by electron impact.

Both similarities and differences are known between the molecular behavior observed under these conditions and that occurring in more conventional chemical environments, in the liquid phase or in gases at higher pressures. Probably the one feature that is most nearly at the heart of the relationships between the chemistries in the two different environments is the limitation of the former to intramolecular processes as opposed to the near ubiquity of intermolecular processes in the latter [19]. To commence the anthropomorphic treatment... At the high vacuum used in the mass spectrometer, at least for the few microseconds during which a molecule is under observation, it never encounters another molecule. It sees itself as alone in the universe - an excited molecule looking for ways to rid itself of the excess energy imparted to it by electron impact, so it can relax, has no neighbors that it can attack. Its only options are to bite its own tail or otherwise reorganize itself and/or to go to pieces, which we refer to as rearrangement and dissociation. When molecules are surrounded by neighbors-as, for example, in solution in a flask or a beaker-if you excite some of them by shining UV light on the solution, or by directing an electron beam into it, or by putting it over a heat source and raising the temperature, the excited molecules can bang against neighboring molecules. They may simply spread the excitation among their neighbors or they may chemically attack one or more of their neighbors, in either case dissipating the energy and thus lowering the level of excitation.

All of this might be summarized by saying that I have been concerned with the individual psychology of molecules, isolated in space, whereas most of conventional chemistry is concerned with their behavior in the presence of great numbers of other molecules, that is, their sociology.

My colleagues and I have studied a set of molecules in which hydrogen atoms are removed from a long flexible chain of carbon atoms and transferred to oxygen atoms that are part of a compact structural grouping [20]. The presence of the originally distant 
hydrogen atoms close enough to the oxygens to allow them to be plucked off the chain and bound to the oxygens suggests that the flexible chain, provided that it is long enough, tends to fold back and coil around the oxygen-containing group, as depicted in Figure 4. Such behavior might be viewed as an attempt to approach conditions in the liquid phase, in which all parts of the molecule are in close contact with the same or neighboring molecules.

In looking for similar behavior in other contexts, the first and perhaps best chemical analogy that I have identified is the polymer chemist's model for flexible polymers in dilute solution in poor solvents [21]. The term "dilute solution" is used here to mean that the solute molecules are so few and so widely dispersed that they only rarely encounter one another. "Poor solvent" means one in which the solute and solvent molecules have chemical characteristics so different that they are unable to relate to each other, like oil and water. A familiar example of such a system is viscosity-index (VI) improvers in lubricating oil. VI improvers are long, flexible molecules that at moderate temperatures are unable to relate chemically to the surrounding oil molecules and hence coil into a tight ball, minimizing the surface exposed to a foreign environment. If the concentration of the solute is increased, solute molecules will meet more frequently, and when they do they will uncoil from the tightly wound balls and coil about each other. That is, they recognize each other as like them and hence as friends and respond accordingly. If the solute is kept in dilute solution but moved to a series of progressively better solvents, a point is reached at which the solute molecules feel enough at home that they uncoil. Alternatively, even in a poor solvent, raising the temperature sufficiently will prompt the solute molecules to uncoil. Thus, the VI improver effectively removes itself from solution at

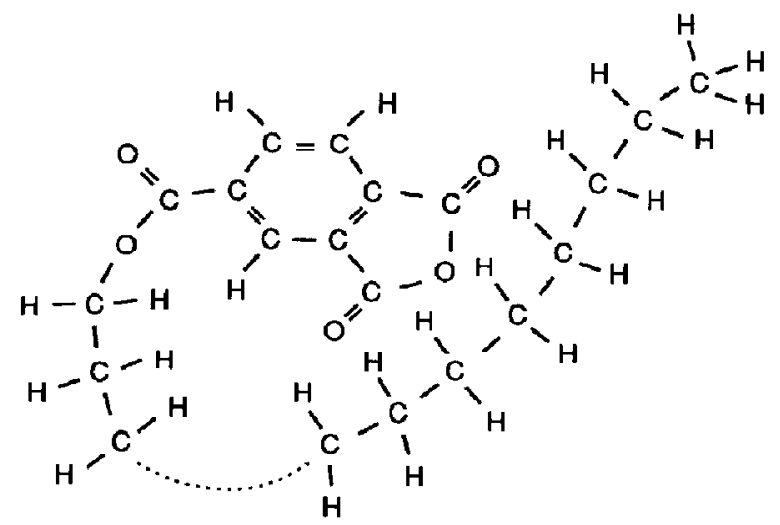

Figure 4. Schematic of alkyl ester of trimellitic anhydride, shown in coiled conformation (see text). For nonchemist readers, each $C$ denotes a carbon atom, $\mathrm{H}$ a hydrogen, and $\mathrm{O}$ an oxygen. $\mathrm{A}$ single line between two atoms denotes a pair of electrons comprising a single bond connecting the atoms; a pair of lines denotes two pairs of electrons comprising a double bond. low temperatures but at higher temperatures goes into solution, where its large size helps to counteract the decrease in oil viscosity brought on by rising temperature. The isolated molecules in the rarefied atmosphere of the mass spectrometer may be considered as an infinitely dilute solution in an infinitely poor solvent. Here, too, raising the initial gas temperature or-as an alternative way to introduce additional excitation energy into the molecules--increasing the energy of the ionizing electrons reduces the extent of the hydrogen migration process and, presumably, the extent of the coiling that makes the hydrogen migration possible.

The analogy may be extended to small aggregates of similar molecules that find themselves surrounded by molecules with very different properties. Thus, drops of liquid poured from a beaker try to attain a spherical shape as they drop through the air; gas bubbles released under the surface of a liquid do likewise as they rise; and monomolecular films of oil on the surface of water tend to form circular islands [22]. Similarly, a recent article on heavy-metal poisoning [23] contains a statement that I found startling. It reads, "In its liquid form, mercury is surprisingly nontoxic-people have ingested ounces with little effect-because it has such a high surface tension that it balls up easily, leaving very little surface area to interact with the body." In each of these instances, a collection of identical or similar molecules, looking out at an environment that it perceives to be different from itself and hence unfriendly, tries to attain a configuration that will minimize the surface exposed to the outside world. The behavior of the VI improver in oil or of the isolated molecule in a high vacuum suggests that this pattern persists as the number of molecules is reduced, down to the limiting case of a single molecule.

Shifting our focus now to the human scene, wherever we look we see that the members of our species have subdivided our communities into categories of people who are seen by others and who see themselves as different from many of their neighbors. We have defined in-groups and out-groups, which we perceive as us and them.

Most obviously, the human race has divided itself into a great number of nations or countries. At a minimum these nations generally set up mechanisms to discourage or at least control movement of people and traffic across their borders. Our history is filled with instances in which nations or blocs of nations have come to view each other as deadly enemies and have resorted to the wholesale killing that we call war. Within a country, we divide ourselves according to all kinds of bases and build barriers to keep the groups apart. We sort people by nationalities determined by where their ancestors came from, often many generations back. We sort them by the regions within the country where they live. We sort them by their belief systems and by political and economic outlooks. We sort them by language. We sort them by skin color, 
sometimes extending this to only slight differences in shading.

Between the groups we establish pecking orders and promote fear and distrust. Within the groups we teach a sense of superiority and preach exclusiveness. In innumerable ways we institute legal restrictions and generate social pressures to ensure that the barriers we have constructed are honored. Even within such groups we reduce further the numbers of people whom we are willing to accept as peers by drawing lines on the basis of age, gender, education, occupation, and income. Some or all of these distinctions, the social mechanisms that keep them in place, and the strong emotional reactions associated with them seem to characterize all human societies. Sometimes, as a result of history and of societal arrangements, these criteria are closely correlated and tend to reinforce each other. Sometimes they may be in conflict. For example, when a nation is at war, animosities between groups within the nation are likely to be temporarily set aside or at least downplayed. An analogy may be drawn here to the uncoiling of VI improvers in a lubricating oil when the temperature of the oil is elevated.

Both the human and molecular behavior patterns described here may be looked on as variants of the defensive strategy associated with homesteaders traveling across the western plains of North America in their covered wagons in the nineteenth century. Fearing possible attacks by hostile Indians, these groups in setting up camp arranged their wagons in a circle, with the women and children on the inside and armed men on guard around the perimeter. $\Lambda$ nonchemist friend, ${ }^{1}$ listening to me expound on the parallelism described here, suggested that it be dubbed "the Conestoga wagon theory," whence the subtitle of this section.

The big difference, of course, between molecules and people in this context is that molecules have no choice. How they will respond to their surroundings is their chemistry; it is an integral part of their being. We huninans, in contrast, can pick and chouse whom we wish to consider as friends or as enemies, as well as define the criteria that we will use to categorize our neighbors. Our history documents any number of instances in which we have expanded markedly the dimensions of our in-groups, increasing with each step the size of the community within which we can feel comfortable. These examples demonstrate that in human communities, unlike molecules, we have the capacity to transform the societal counterpart of a poor solvent to that of a good solvent by purposeful action and do not need a rise in temperature to prompt us to uncoil. Ultimately we can expand the group within which we feel at home to embrace the entire human race. We have choices.

\footnotetext{
${ }^{1}$ Professor Frederick C. Stern, English Department, University of Illinois at Chicago.
}

Finally, during the past 30 years or so, computers have become integral parts of nearly all mass spectrometer installations. Hence 1 feel obligated to include them also in this presentation. The case for computers is nicely summarized in an article that appeared in the University of Chicago Magazine some months $\mathrm{ago}^{2}$ [24]:

A man has an immensely powerful computer into which he has fed vast amounts of information. He asks it, "[Can] you compute whether you will ever think like a human being?" Whirring away, the machine goes through its computations. Finally, it prints out its answer: "I'HA'I' REMINDS ME OF' A SIORY."

\section{Acknowledgments}

I thank the Amoco Corporation management and many staff members for the continuing help and courtesies extended to me during the years since my retirement, particularly with the preparation of this article.

\section{References}

1. Mohler, F. L.; Dibeler, V. H,; Williamson, L.; Dean, M. I. Res. Natl. Bur. Stand. 1952, 48, 188.

2. Rylander, P. N.; Meyerson, S: Grubh, H. M. J. Am. Chem. Soc 1957, 79, 842.

3. Meyerson, S.; Rylander, P. N. I. Chem. Phys. 1957, 27, 901.

4. Rylander, P. N.; Meyerson, S. J. Am. Chem. Soc. 1956, 78, 5799.

5. Meyerson, S. Org. Mass Spectrom. 1989, 24, 267.

6. MeCrery, D. A.; Freiser, B. S. Presented at the 26th Annual ASMS Conference on Mass Spectrometry and Allied Topics; St. Louis, MO, May 28-June 2, 1978; paper WC7.

7. Meyerson, S. Anal. Chem. 1961, 33, 964.

8. Shields, W. R.; Murphy, T. J.; Garner, E. L.; Dibeler, V. H. J. Am. Chem. Soc. 1962, 84, 1519.

9. Busch, K. L.; Bursey, M. M.; Hass, J. R.; Sovocool, G. W. Appl. Spectrosc. 1978, 32, 388.

10. (a) Butcher, W. W.; Westheimer, F. H. I. Am. Chem. Soc. 1955, 77. 2420; (b) Barnard, D. W. C.; Bunton, C. A.; Llewellyn, D. R.; Oldham, K. G.; Silver, B. L.; Vernon, C. A. Chem. Ind. (Lonaion) 1955, 760; (c) Bunton, C. A.; Llewellyn, D. R.; Oldham, K. G.; Vernon, C. A. I. Chem. Soc. 1958, 3574; (d) Bunton, C. A. Acc. Chem. Res. 1970, 3, 257.

11. (a) Brown, D. M; Hamer, N. K. I. Chem. Soc 196n, 11.55; (b) DiSabato, G.; Jencks, W. P. J. Am. Chem. Soc, 1961, 83, 4400; (c) Jencks, W. P. Catalysis in Chemistry and Enzymology; McGraw-Hill, New York; 1969, pp 81-83, 103-105, 112-115; (d) Kirby, A. J.; Varvoglis, A. G. J. Am. Chem. Soc. 1967, 89, 415; (e) Gorenstein, D. G.; Lee, Y. G.; Kar, D. J. Am. Chem. Soc. $1977,99,2264$.

12. Rebek, J.; Gavina, F.; Navarro, C. J. Am. Chem. Soc. 1978, 100, 8113.

13. Yoke, J. T. I. Am. Chem. Soc. 1978, 100, 1978.

14. Harvan, D. J.; Hass, J. R.; Busch, K. L.; Bursey, M. M.; Ramirez, F.; Meyerson, S. J. Am. Chem. Soc. 1979, 101, 7409;

\footnotetext{
${ }^{2}$ The story is there attributed to Gregory Bateson.
} 
for the subsequent full paper, see Meyerson, S.; Harvan, D. J.; Hass, J. R.; Ramirez, F.; Marecek, J. R. I. Am. Chem. Soc. 1984, 106,6877 .

15. Meyerson, S.; Kuhn, E. S.; Ramirez, F.; Marecek, J. F.; Okazaki H. J. Am. Chem. Soc. 1978, 100, 4062.

16. Leffler, J. E. The Reactive Intermediates of Organic Chemistry; Wiley (Interscience). New York, 1956, pp 117 and 130

17. Meyerson, S. Org. Mass Spectrom. 1986, 21, 197.

18. Jones, G. G.; Meyerson, S. CHEMTECH 1979, 9, 560.

19. Meyerson, S. CHEMTECH 1979, 9, 560.

20. (a) Meyerson, S.; Puskas, I.; Fields, E. K. Chem. Ind. (London) 1968, 1845; (b) Meyerson, S.; Puskas, I.; Fields, E. K. Adv.
Mass Spectrom. 1974, 6, 17; (c) Meyerson, S.; Puskas, I.; Fields, E. K. J. Am. Chem. Soc. 1973, 95, 6056; see also (d) Cable, J.; Djerassi, C. J. Am. Chem. Soc. 1971, 93, 3905.

21. See, for example, (a) Rodriguez, F. Principles of Polymer Systems; McGraw-Hill, New York, 1970; p 152; (b) Tanford, C. Physical Chemistry of Macromolecules; Wiley, New York, 1961; Pp 405-406; (c) Vrij, A. J. Polymer Sci. (A-2) 1969, 7, 1627; and references cited therein.

22. (a) Ries, H. E., private communication, 1957; (b) Zimmer, $\mathrm{C}$ Discover 1992, 13, 103.

23. Weaver, D. C. Discover 1993, 14, 76.

24. Kalven, J. Univ. Chicago Mag. 1992, 6, 34. 